\title{
Pó de coco como substrato para produção de mudas de tomateiro
}

\author{
Elineide B. Silveira ${ }^{1}$; Viviane J.L.B. Rodrigues ${ }^{1}$; Andréa M.A. Gomes ${ }^{1}$; Rosa L.R. Mariano; Júlio C.P. \\ Mesquita $^{2}$ \\ ${ }^{1}$ UFRPE, 52.171-900 Recife-PE; ${ }^{2}$ Engenheiro Agrônomo-Produtor. E-mail: elineidebs@yahoo.com.br
}

\begin{abstract}
RESUMO
A produção de mudas constitui uma das etapas mais importantes do sistema produtivo hortícola, sendo altamente dependente da utilização de insumos. Avaliou-se o potencial do pó de coco, isolado e em combinação com outros substratos [pó de coco, Plantmax ${ }^{\circledR}$ e húmus de minhoca e as misturas em iguais proporções $(\mathrm{v} / \mathrm{v})$ Plantmax ${ }^{\circledR}+$ pó de coco, húmus de minhoca + pó de coco, Plantmax ${ }^{\circledR}+$ húmus de minhoca e Plantmax ${ }^{\circledR}+$ pó de coco + húmus de minhoca], para produção de mudas de tomateiro 'Santa Adélia'. Avaliou-se aos 10 dias após semeadura, a variável germinação e, aos 25 dias após a semeadura, as variáveis número de folhas, altura da planta e matéria fresca e seca da parte aérea. A mistura entre substratos foi mais favorável à produção de mudas de tomateiro, com destaque para os tratamentos Plantmax ${ }^{\circledR}+$ pó de coco + húmus de minhoca. A microbiota natural de cada um dos três substratos foi quantificada com relação às variáveis bactérias totais, fungos totais, Pseudomonas do grupo fluorescente, Bacillus e Trichoderma. Nos substratos pó de coco e húmus de minhoca a população bacteriana superou a fúngica. Húmus de minhoca e pó de coco se destacaram, respectivamente com maior população de bactérias totais $(240,56 \mathrm{x}$ $10^{4} \mathrm{UFC} / \mathrm{g}$ de substrato seco) e fungos totais $\left(86,98 \times 10^{4} \mathrm{UFC} / \mathrm{g}\right.$ de substrato seco). Pseudomonas spp. fluorescentes foram detectadas em húmus de minhoca $\left(1,65 \times 10^{4} \mathrm{UFC} / \mathrm{g}\right.$ de substrato seco) e Plantmax ${ }^{\circledR}\left(0,36 \times 10^{4} \mathrm{UFC} / \mathrm{g}\right.$ de substrato seco $)$; Bacillus spp. em húmus de minhoca $\left(33,23 \times 10^{4} \mathrm{UFC} / \mathrm{g}\right.$ de substrato seco) e; Trichoderma spp. apenas em pó de coco $\left(2,42 \times 10^{4} \mathrm{UFC} / \mathrm{g}\right.$ de substrato seco). Para avaliar o efeito do incremento da microbiota natural dos substratos na promoção de crescimento de plântulas de tomateiro foram adicionadas as misturas Plantmax ${ }^{\circledR}+$ húmus de minhoca; Plantmax ${ }^{\circledR}+$ pó de coco e; Plantmax ${ }^{\circledR}+$ pó de coco + húmus de minhoca suspensões de cinco isolados de Trichoderma spp, quatro isolados de Pseudomonas fluorescentes, cinco isolados de Bacillus spp. e a mistura dos isolados Trichoderma + Pseudomonas fluorescentes + Bacillus. As suspensões foram adicionadas dois dias antes do plantio, na concentração de 0,52 A e $5 \times 10^{6}$ conídios $/ \mathrm{mL}$ para bactérias e fungos, respectivamente. $\mathrm{O}$ incremento da população microbiana dos substratos não promoveu o crescimento das plântulas de tomateiro. Conclui-se que a utilização de pó de coco em mistura com outros substratos, principalmente com o Plantmax ${ }^{\circledR}$, é viável barateando o custo de produção de mudas de tomateiro.
\end{abstract}

Palavras-chave: Lycopersicon esculentum, Pseudomonas spp. fluorescentes, Bacillus spp., Trichoderma spp., pó de coco, Plantmax ${ }^{\circledR}$, húmus de minhoca, fungos, bactérias.

\author{
ABSTRACT \\ Coconut coir fiber as a potting media for tomato seedling \\ production
}

The production of seedlings is very important in the horticultural transplant industry and depends on the substrate utilization. The use of coconut coir fiber alone was evaluated or in combination with other potting media to produce transplants of tomato cv. 'Santa Adélia'. Cococnut coir fiber potting media Plantmax ${ }^{\circledR}$ and earthworm castings were tested separated and in volumetric combinations: Plantmax ${ }^{\circledR}+$ cocunut coir fiber, worm cast + cocunut coir fiber, Plantmax ${ }^{\circledR}+$ earthworm casting and Plantmax ${ }^{\circledR}+$ coconut coir fiber + earthworm casting, evaluating the variables germination 10 days after planting, leaf number, plant height, shoot fresh matter and shoot dry matter at 25 days after planting. The mixed substrates were superior to those from single components mainly Plantmax ${ }^{\circledR}+$ coconut coir fiber + earthworm casting. The indigenous microbial population in each one of the three substrates was quantified in relation to the variables total bacteria, total fungi, fluorescent Pseudomonas spp., Bacillus and Trichoderma. In coconut coir fiber and earthworm casting the bacterial population surpassed the fungal. Earthworm casting and coconut coir fiber showed respectively higher population of total bacteria $\left(240.56 \times 10^{4} \mathrm{UFC} / \mathrm{g}\right.$ of dry substrate $)$ and total fungi ( $86.98 \times 10^{4} \mathrm{UFC} / \mathrm{g}$ of dry substrate). Fluorescent Pseudomonas spp. were detected in earthworm casting $\left(1.65 \times 10^{4}\right.$ UFC/g of dry substrate $)$ and Plantmax ${ }^{\circledR}\left(0.36 \times 10^{4} \mathrm{UFC} / \mathrm{g}\right.$ of dry substrate); Bacillus spp. in earthworm casting (33.23 x $10^{4} \mathrm{UFC} / \mathrm{g}$ of dry substrate) and, Trichoderma spp. only in coconut coir fiber $\left(2.42 \times 10^{4} \mathrm{UFC} / \mathrm{g}\right.$ of dry substrate). To evaluate the effect of increment of the indigenous microbial population of substrates in promotion of seedlings growth of tomato Plantmax ${ }^{\circledR}+$ coconut coir fiber + earthworm casting suspensions of five isolates of Trichoderma spp.; four isolates of fluorescent Pseudomonas spp., five isolates of Bacillus and the mixed of the isolates Trichoderma + fluorescent Pseudomonas spp. + Bacillus were added. The suspensions were added two days before planting, on concentrations of $0.52 \mathrm{~A}$ and $5 \times 10^{6}$ conidia $/ \mathrm{mL}$ to bacteria and fungi, respectively. The increment of microbial population did not affect the growth of tomato seedlings. In conclusion, the utilization of the coconut coir fiber mixed with other substrates, mainly Plantmax ${ }^{\circledR}$, is viable reducing the costs of tomato seedling production.

Keywords: Lycopersicon esculentum, fluorescent Pseudomonas spp., Bacillus spp., Trichoderma spp, coconut coir fiber, Plantmax ${ }^{\circledR}$, earthworm casting, fungi, bacteria.

\section{(Aceito para publicação em 31 de janeiro de 2.002)}

\begin{abstract}
A produção de mudas constitui-se numa das etapas mais importantes do sistema produtivo hortícola, uma vez que dela depende o desempenho final das plantas nos canteiros de produção,
\end{abstract}

tanto do ponto de vista nutricional, quanto do tempo necessário à produção $\mathrm{e}$, consequentemente, do número de ciclos produtivos possíveis por ano (Carmello, 1995). Essa produção é altamente de- pendente da utilização de insumos. Neste contexto, o substrato é um dos insumos que tem se destacado em importância devido à sua ampla utilização na produção de mudas de hortaliças. 
O substrato hortícola pode ser conceituado como o meio onde se desenvolvem as raízes das plantas produzidas em sementeiras e/ou viveiros de mudas olerícolas, ornamentais, frutíferas ou silvícolas (Carneiro, 1995). Ele deve garantir por meio de sua fase sólida a manutenção mecânica do sistema radicular e estabilidade da planta; da fase líquida o suprimento de água e nutrientes e; da fase gasosa, o suprimento de oxigênio e o transporte de dióxido de carbono entre as raízes e o ar externo (Lamaire, 1995). Deve ainda estar isento de elementos minerais ou qualquer outra substância em concentração fitotóxica, assim como de fitopatógenos, pragas e plantas indesejáveis (Carneiro, 1995; Minami, 1995). Desta maneira, a escolha do substrato é uma das decisões mais importantes para produtores de mudas, principalmente quando se sabe que as condições ideais de cultivo dependem do tipo de exigência das espécies cultivadas. Segundo Minami (1995), 60\% do sucesso de uma cultura residem no plantio de mudas de boa qualidade.

Com a modernização da agricultura e a segmentação do mercado, surgiu a especulação na atividade de produção de mudas (Luz et al., 2000). Existem substratos comerciais empregados nesta atividade que são de boa qualidade, porém seu custo é elevado. Uma medida adequada consiste em utilizar substratos regionais que possam ser obtidos facilmente, tal como o pó de coco. Este é um resíduo orgânico derivado do mesocarpo fibroso do coco e tem se mostrado como uma alternativa para a redução dos custos dos substratos, com resultados positivos no desenvolvimento de plântulas de diversas culturas (Meerow, 1994; Pragana, 1998).

Com relação à qualidade dos substratos, um aspecto pouco estudado é o efeito da microbiota natural na qualidade das mudas produzidas. Sabe-se que a microbiota do solo exerce efeitos diretos e indiretos na produtividade e na qualidade dos produtos agrícolas (Siqueira \& Franco, 1988) e, provavelmente, as populações microbianas naturais dos substratos de mudas desempenham funções similares às do solo, tais como decomposição de resíduos orgânicos com a liberação de nutrientes e $\mathrm{CO}_{2}$; produção de substâncias estimuladoras do crescimento vegetal; estabelecimento de simbiose mutualista com plantas e; controle biológico de pragas e doenças.

O objetivo deste trabalho foi avaliar o potencial do pó de coco, isolado e em combinação com Plantmax ${ }^{\circledR}$ e húmus de minhoca, na produção de mudas de tomateiro, bem como o efeito do incremento de alguns gêneros da microbiota natural dos substratos na promoção de crescimento dessas mudas.

\section{MATERIAL E MÉTODOS}

Os experimentos foram conduzidos em casa de vegetação e em laboratório da UFRPE, de outubro/99 a fevereiro/00.

Influência de substratos na qualidade de mudas de tomateiro

Para a produção de mudas de tomateiro comparou-se o substrato comercial Plantmax ${ }^{\circledR}$ (segundo o fabricante constitui-se de mistura de matéria orgânica de origem vegetal e vermiculita expandida), húmus de minhoca (resíduo de esterco bovino, obtido por processo de digestão das minhocas), pó de coco, resíduo orgânico (derivado do mesocarpo fibroso do coco) e as misturas Plantmax $\AA^{\circledR}+$ pó de coco; húmus de minhoca + pó de coco; Plantmax ${ }^{\circledR}+$ húmus de minhoca; e Plantmax ${ }^{\circledR}+$ pó de coco + húmus de minhoca, em iguais proporções (volume/volume).

Sementes de tomateiro cv. Santa Adélia foram semeadas nos diferentes substratos contidos em bandejas de poliestireno expandido, com 128 células, na profundidade de $0,5 \mathrm{~cm}$, colocando-se duas sementes no centro de cada célula da bandeja. $O$ desbaste foi realizado aos dez dias após a semeadura, deixando-se uma plântula por célula. As plântulas foram mantidas em condições de casa de vegetação (temperatura de $30 \pm 5^{\circ} \mathrm{C}$ e umidade relativa do ar de $75 \%$ ), e submetidas à irrigação manual com início logo após a semeadura, duas aplicações diárias.

Aos 10 dias após a semeadura foi analisada a variável geminação e, aos 25 dias após a semeadura, o número de folhas, altura das plantas, matéria fresca da parte aérea e matéria seca da parte aérea. Para determinação da matéria seca, as plantas foram submetidas à temperatura de $80^{\circ} \mathrm{C}$, em estufa, por 48 horas.

$\mathrm{O}$ delineamento experimental foi inteiramente casualizado, com quatro repetições, sendo a unidade experimental constituída por oito plantas. Os dados obtidos foram submetidos à análise de variância e as médias comparadas pelo teste de Duncan ao nível de 5\% de probabilidade.

Os dados de custo dos substratos foram obtidos junto aos produtores de mudas de hortaliças da Zona da Mata de Pernambuco.

\section{Detecção da microbiota natural dos substratos}

Para detectar a microbiota natural dos substratos, de cada amostra dos substratos Plantmax ${ }^{\circledR}$, húmus de minhoca e pó de coco, $10 \mathrm{~g}$ de substrato seco foram pesadas, colocadas em Erlenmeyer com $90 \mathrm{~mL}$ de água de torneira esterilizada (ATE) e homogeneizado em liquidificador por 1 minuto. Desta suspensão, $1 \mathrm{~mL}$ foi transferido para tubo contendo $9 \mathrm{~mL}$ de ATE, e assim sucessivamente, fazendo-se diluições em série na base 10 até $10^{-5}$. As suspensões foram homogeneizadas em agitador Vórtex e alíquotas de $0,1 \mathrm{~mL}$ das diluições $10^{-3} ; 10^{-4}$ e $10^{-5}$ foram plaqueadas em meio de cultura, sendo espalhadas uniformemente com alça de Drigalsky. Foram analisadas as variáveis: população de bactérias totais, fungos totais, Pseudomonas do grupo fluorescente, Bacillus e Trichoderma. O meio de cultura NYDA (Pusey \& Wilson, 1984) foi utilizado para o isolamento de bactérias totais e o meio B de King (King et al., 1954), para isolamento diferencial de Pseudomonas spp. do grupo fluorescente. Para o isolamento seletivo de bactérias do gênero Bacillus, a primeira diluição $\left(10^{-1}\right)$ foi submetida a banho-maria de $80^{\circ} \mathrm{C}$ por 10 minutos (Sneath, 1986) e as diluições plaqueadas em meio BDA (Tuite, 1969). A todos os meios de cultura foi adicionado o fungicida benomil (250 ppm). Para detecção dos fungos totais presentes nos diferentes substratos foi utilizado o meio BDA e, para isolamento seletivo de fungos do gênero Trichoderma, o meio de Martin (Tuite, 1969), ambos com rifampicina $(250 \mathrm{ppm})$. As placas foram 
Tabela 1. Germinação e crescimento de mudas de tomateiro em diferentes substratos. Recife, UFRPE, 2000.

\begin{tabular}{|c|c|c|c|c|c|}
\hline Substrato & $\underset{\%}{\text { Germinação }}$ & $\begin{array}{l}\text { Altura } \\
\text { cm }\end{array}$ & $\begin{array}{l}\text { Número de } \\
\text { folhas }\end{array}$ & $\begin{array}{c}\text { Matéria fresca } \\
\text { parte aérea } \\
\text { mg }\end{array}$ & $\begin{array}{c}\text { Matéria seca } \\
\text { parte aérea } \\
\text { mg }\end{array}$ \\
\hline$P+P C+H^{1}$ & 89,06 a & $17,78 \mathrm{a}$ & $3,44 \mathrm{a}$ & $957,5 \mathrm{a}$ & $85,0 \mathrm{a}$ \\
\hline$P+P C$ & $85,94 a b$ & $17,61 \mathrm{a}$ & $3,25 \mathrm{a}$ & 877,5 a & 75,0 a \\
\hline $\mathrm{P}+\mathrm{H}$ & $76,56 a b$ & $16,70 a b$ & $3,34 \mathrm{a}$ & $790,0 a b$ & $70,0 \mathrm{a}$ \\
\hline $\mathrm{PC}+\mathrm{H}$ & 93,75 a & $12,10 \quad c$ & $2,44 \quad b$ & $392,5 \mathrm{~cd}$ & $37,5 \quad b$ \\
\hline $\mathrm{P}$ & $67,18 \quad b$ & $14,00 \quad b c$ & $2,37 \quad b$ & $555,0 \quad b c$ & $30,0 \quad b c$ \\
\hline $\mathrm{H}$ & $73,44 a b$ & $8,97 \quad d$ & $2,00 \quad b$ & $210,0 \quad \mathrm{de}$ & $17,5 \mathrm{bc}$ \\
\hline $\mathrm{PC}$ & 90,63 a & 4,45 & 1,03 & 35,0 & $10,0 \quad c$ \\
\hline CV (\%) & 16,11 & 14,96 & 11,68 & 31,72 & 32,39 \\
\hline
\end{tabular}

*/ Médias de quatro repetições. Médias seguidas da mesma letra na vertical não diferem entre si pelo teste Duncan, ao nível de 5\% de probabilidade;

1/ Substratos: $\mathrm{P}=$ Plantmax $® ; \mathrm{PC}=$ pó de coco; $\mathrm{H}=$ húmus de minhoca.

incubadas em condições de laboratório $\left(28 \pm 2{ }^{\circ} \mathrm{C}\right)$, sendo as populações bacterianas e fúngicas avaliadas após 36-48 horas e 4 dias, respectivamente, nas diluições onde foi possível quantificar a população em unidades formadoras de colônias por grama de substrato seco (UFC/g de substrato seco) por placa. Para a enumeração da população microbiana foi utilizado um contador de colônias. O cálculo do número de microrganismos em UFC/g de substrato seco foi resultante do número de colônias x diluição da amostra x 10 . Este último fator refere-se ao ajuste do plaqueamento para $1 \mathrm{~mL}$ de suspensão por placa. Os dados foram transformados para uma mesma base de 10 (Mariano et al., 2000). Colônias isoladas de bactérias e fungos foram repicadas para tubos contendo NYDA e BDA, respectivamente, e cultivadas por três a nove dias à temperatura ambiente $\left(28 \pm 2{ }^{\circ} \mathrm{C}\right)$.

$\mathrm{O}$ delineamento experimental foi inteiramente casualizado, com cinco repetições, sendo a unidade experimental constituída por uma placa de Petri. Os dados obtidos foram submetidos à análise de variância e as médias comparadas pelo teste de Duncan ao nível de $5 \%$ de probabilidade.

Influência do incremento da microbiota natural dos substratos na promoção de crescimento de plântulas de tomateiro

Para avaliar a influência do incremento da microbiota natural dos substratos na promoção de crescimento de plântulas de tomateiro, foram adicionadas às misturas Plantmax ${ }^{\circledR}+$ húmus de minhoca; Plantmax ${ }^{\circledR}+$ pó de coco e; Plantmax ${ }^{\circledR}+$ pó de coco + húmus de minhoca, suspensões de cinco isolados de Trichoderma spp, quatro isolados de Pseudomonas fluorescentes, cinco isolados de Bacillus spp. e a mistura dos isolados Trichoderma + Pseudomonas fluorescentes + Bacillus, selecionados aleatoriamente entre a população de microrganismos obtidos desses substratos. As suspensões foram adicionadas dois dias antes do plantio, na concentração de $0,52 \mathrm{~A}$ (absorvância em fotocolorímetro a $580 \mathrm{~nm}$ ) e $5 \times 10^{6}$ conídios $/ \mathrm{mL}$ para bactérias e fungos, respectivamente. As metodologias utilizadas na semeadura e a avaliação foram as mesmas descritas no primeiro experimento.

O delineamento experimental foi inteiramente casualizado em arranjo fatorial $3 \times 5$, representado por três misturas de substratos e quatro grupos de microrganismo além da testemunha. Foram utilizadas quatro repetições, sendo a unidade experimental constituída por oito plantas. Os dados obtidos foram submetidos à análise de variância e as médias comparadas pelo teste de Duncan ao nível de $5 \%$ de probabilidade.

\section{RESULTADOS E DISCUSSÃO}

A emergência do tomateiro ocorreu, de uma maneira geral, no $5^{\circ}$ dia após a semeadura, encontrando-se a maior porcentagem de plantas emergidas no $10^{\circ}$ dia após semeadura $(93,75 \%)$ na combinação pó de coco + húmus de minhoca, porém não diferiu do pó de coco, húmus de minhoca e das demais misturas e foi superior apenas ao Plantmax ${ }^{\circledR}$, onde a emergência foi de apenas $67,18 \%$ (Tabela 1). Detectou-se uma boa germinação em todos os tratamentos onde o pó de coco estava presente, provavelmente devido à alta capacidade de retenção de água desse substrato, a qual foi verificada por Pragana (1998), e que proporciona uma condição ideal para a germinação das sementes de tomate. Apesar de uma excelente emergência do tomateiro no pó de coco puro $(90,63 \%)$, este não se revelou bom substrato, pois nele as plântulas não apresentaram bom desenvolvimento, sendo inferior aos obtidos nas misturas com pó de coco, em relação às variáveis altura da planta, número de folhas e matéria fresca e seca da parte aérea. Isto indica que para ser eficiente como substrato esse material deverá ser empregado em mistura com outros materiais mais ricos em nutrientes. De acordo com Pragana (1998), o pó de coco, a julgar pela baixa condutividade elétrica, apresenta um teor baixo de nutrientes e sais. No húmus de minhoca puro, no Plantmax ${ }^{\circledR}$ puro e na combinação pó de coco + húmus de minhoca, as plântulas também apresentaram desenvolvimento retardado em relação às variáveis altura, número de folhas e matéria fresca e seca da parte 
Tabela 2. População de microrganismos em diferentes substratos agrícolas. Recife, UFRPE, 2000.

\begin{tabular}{lccccccc}
\hline Substrato & $\begin{array}{c}\text { Bactérias }_{\text {totais }}{ }^{1} \\
\text { Fungos totais }\end{array}$ & $\begin{array}{c}\text { Pseudomonas } \\
\text { spp. } \\
\text { fluorescentes }\end{array}$ & Bacillus spp. & $\begin{array}{c}\text { Trichoderma } \\
\text { spp. }\end{array}$ \\
\hline Plantmax $\mathbb{R}$ & 6,97 & $\mathrm{~b}$ & $10,13 \mathrm{~b}$ & $0,36 \quad \mathrm{~b}$ & $0,00 \mathrm{~b}$ & $0,00 \mathrm{~b}$ \\
Húmus de minhoca & $240,56 \mathrm{a}$ & $2,14 \quad \mathrm{C}$ & $1,65 \mathrm{a}$ & $33,23 \mathrm{a}$ & $0,00 \mathrm{~b}$ \\
Pó de coco & $176,97 \mathrm{a}$ & $86,98 \mathrm{a}$ & $0,00 \quad \mathrm{~b}$ & $0,00 \quad \mathrm{~b}$ & $2,42 \mathrm{a}$ \\
\hline $\mathrm{CV}(\%)$ & 16,27 & 13,82 & 22,05 & 41,04 & 21,37 \\
\hline
\end{tabular}

*/ Médias de cinco repetições. Médias seguidas da mesma letra na vertical não diferem entre si pelo teste Duncan, ao nível de 5\% de probabilidade;

1/ Dados transformados segundo raiz $(\mathrm{x}+1)$.

aérea, quando comparado aos tratamentos Plantmax ${ }^{\circledR}+$ pó de coco + húmus de minhoca, Plantmax ${ }^{\circledR}+$ pó de coco e Plantmax ${ }^{\circledR}+$ húmus de minhoca.

A mistura Plantmax $®+$ pó de coco + húmus de minhoca produziu os maiores valores de altura $(17,78 \mathrm{~cm})$, número de folhas $(3,44)$, matéria fresca da parte aérea $(957,5 \mathrm{mg})$ e matéria seca da parte aérea $(85,0 \mathrm{mg})$, mas não diferiu significativamente das misturas Plantmax ${ }^{\circledR}+$ pó de coco e Plantmax ${ }^{\circledR}$ + húmus de minhoca (Tabela 1). Pragana (1998), em testes de bioensaio com diversas hortaliças, verificou que, de modo geral, a adição do pó de coco ao Plantmax ${ }^{\circledR}$, ao composto orgânico ou a vermiculita melhorou significativamente o desempenho destes, e também em relação a si próprio isoladamente. Os dois substratos formulados contendo o pó de coco e o Plantmax ${ }^{\circledR}$ (Plantmax ${ }^{\circledR}$ + pó de coco e Plantmax ${ }^{\circledR}+$ pó de coco + húmus de minhoca) proporcionaram o melhor desenvolvimento vegetativo das plântulas, medido pela matéria fresca e seca da parte aérea, quando comparado ao substrato Plantmax ${ }^{\circledR}$ utilizado pelos produtores de mudas de tomateiro da Zona da Mata de Pernambuco, o que se deve, provavelmente, às melhores combinações entre as propriedades físicas e químicas desses substratos.

$\mathrm{Na}$ análise microbiológica dos substratos, a população bacteriana superou a fúngica nos substratos húmus de minhoca e pó de coco (Tabela 2). O maior número de bactérias foi detectado em húmus de minhoca $\left(240,56 \times 10^{4}\right.$ UFC/g de substrato seco) sem diferir significativamente do pó de coco (176,97 x 104 UFC/g de substrato seco).
O húmus de minhoca, considerado por Soarez (1999) como ideal para cultivo, deve apresentar uma população bacteriana variando de $5 \times 10^{8}$ a $2 \times 10^{12}$ UFC/g de substrato. A população encontrada no húmus de minhoca no nosso estudo está um pouco abaixo do indicado, porém variações podem ser encontradas entre amostras em função do estado de decomposição e a qualidade do material utilizado para alimentação das minhocas.

Com relação à população fúngica, o maior número de isolados foi encontrado em pó de coco $\left(86,98 \times 10^{4} \mathrm{UFC} / \mathrm{g}\right.$ de substrato seco), que diferiu significativamente dos demais, os quais apresentaram populações inferiores a $11 \mathrm{x}$ $10^{4} \mathrm{UFC} / \mathrm{g}$ de substrato seco. No caso de populações microbianas em solos, sabe-se que as bactérias se apresentam em maior quantidade do que os fungos, estando as populações estimadas, respectivamente, em cerca de $10^{8}$ a $10^{9}$ e $10^{4}$ a $10^{6}$ organismos por grama de solo (Brandão, 1992).

Isolamentos diferenciais ou seletivos foram realizados para Pseudomonas fluorescentes, Bacillus e Trichoderma, pois estes gêneros apresentam variadas espécies descritas como potenciais agentes de biocontrole e promoção de crescimento, inclusive com produtos já registrados e comercializados para o controle de organismos alvos causadores de doenças em sementeiras de tomate. Como exemplo, podem ser citados Kodiak (Bacillus subtilis) e Trieco (Trichoderma viride), indicados para o controle de Rhizoctonia spp., Pythium spp. e Fusarium spp., agentes causais de tombamentos em plântulas (Fravel, 2000).
As bactérias Pseudomonas spp. do grupo fluorescente foram detectadas em maior quantidade em húmus de minhoca $\left(1,65 \times 10^{4} \mathrm{UFC} / \mathrm{g}\right.$ de substrato seco). O substrato Plantmax ${ }^{\circledR}$, apesar de apresentar uma baixa população bacteriana total $\left(6,97 \times 10^{4} \mathrm{UFC} / \mathrm{g}\right.$ de substrato seco), parte desta foi constituída por Pseudomonas spp. fluorescentes $\left(0,36 \times 10^{4} \mathrm{UFC} / \mathrm{g}\right.$ de substrato solo $)$. O substrato pó de coco não apresentou este grupo de bactérias pelo método utilizado (Tabela 2). Algumas espécies de Pseudomonas spp. fluorescentes atuam promovendo o crescimento de plantas ou reduzindo as populações de microrganismos deletérios que causam inibição do crescimento de plantas e deformações de raízes (Melo, 1998).

Populações de Bacillus spp. foram detectadas em grande quantidade no húmus de minhoca $\left(33,23 \times 10^{4} \mathrm{UFC} / \mathrm{g}\right.$ de substrato seco). Nos substratos Plantmax ${ }^{\circledR}$ e pó de coco não foi verificada a presença do referido gênero (Tabela 2). As espécies de Bacillus têm sido aplicadas a substratos para produção de mudas antes ou imediatamente após o plantio para controlar fitopatógenos, tendo grande potencial de uso como inoculante, pois produzem endosporos que são termotolerantes e resistentes à dessecação, irradiação U.V. e solventes orgânicos (Melo, 1998).

Espécies de Trichoderma foram detectadas apenas no substrato pó de coco $\left(2,42 \times 10^{4} \mathrm{UFC} / \mathrm{g}\right.$ de substrato seco) (Tabela 2). Trichoderma spp. são fungos micoparasitas necrotróficos e utilizados com sucesso no controle de diversos patógenos, tais como Pythium spp. e Rhizoctonia spp., causadores de 
Tabela 3. Germinação e crescimento de mudas de tomateiro com a inoculação de alguns gêneros da microbiota natural dos substratos. Recife, UFRPE 2000.

\begin{tabular}{|c|c|c|c|c|c|c|c|}
\hline Variável & Substrato ${ }^{1}$ & $\begin{array}{c}\text { Trichoderma } \\
\text { spp. }\end{array}$ & $\begin{array}{l}\text { Pseudomo- } \\
\text { nas spp. }\end{array}$ & $\begin{array}{l}\text { Bacillus } \\
\text { spp. }\end{array}$ & $T+P+B$ & Testemunha & CV (\%) \\
\hline \multirow[t]{3}{*}{ Germinação (\%) } & $\mathrm{P}+\mathrm{PC}+\mathrm{H}$ & 85,00 a $A$ & 85,25 a $A$ & 85,00 a $A$ & 79,75 a $A$ & 81,75 a $A$ & 22,27 \\
\hline & $P+P C$ & 81,00 a $A$ & 80,75 a $A$ & 79,75 a $A$ & 80,25 a $A$ & 80,25 a $A$ & \\
\hline & $\mathrm{P}+\mathrm{H}$ & 81,75 a $A$ & 78,75 a $A$ & 82,25 a A & 79,50 a $A$ & 85,00 a $A$ & \\
\hline \multirow[t]{3}{*}{ Altura $(\mathrm{cm})$} & $\mathrm{P}+\mathrm{PC}+\mathrm{H}$ & 13,35 a $A$ & 12,69 a $A$ & 12,75 a $A$ & 13,05 a $A$ & 12,34 a $A$ & 8,64 \\
\hline & $P+P C$ & 10,92 a $A$ & 11,20 a $A$ & 11,03 a $A$ & 10,90 a $A$ & 10,20 a $A$ & \\
\hline & $\mathrm{P}+\mathrm{H}$ & 12,90 a $A$ & 13,45 a $A$ & 12,01 a A & 12,75 a $\mathrm{A}$ & 12,33 a $A$ & \\
\hline \multirow{3}{*}{$\begin{array}{l}\text { Número de } \\
\text { folhas }\end{array}$} & $\mathrm{P}+\mathrm{PC}+\mathrm{H}$ & 3,54 a $A$ & 3,54 a $A$ & 3,50 a $A$ & 3,53 a $A$ & 3,34 a $A$ & 10,0 \\
\hline & $P+P C$ & 2,96 a $A$ & 3,04 a $A$ & 2,87 a $A$ & 2,78 a $A$ & 2,71 a $A$ & \\
\hline & $\mathrm{P}+\mathrm{H}$ & 3,56 a $A$ & 3,50 a $A$ & 3,44 a $A$ & 3,50 a $A$ & 3,62 a $A$ & \\
\hline \multirow{3}{*}{$\begin{array}{l}\text { Matéria fresca } \\
\text { parte aérea }(\mathrm{mg})\end{array}$} & $\mathrm{P}+\mathrm{PC}+\mathrm{H}$ & 1090,0 a A & 1020,0 a $A$ & 1120,0 a $A$ & 1130,0 a $A$ & 1000,0 a A & 18,44 \\
\hline & $\mathrm{P}+\mathrm{PC}$ & 800,0 a $A$ & 900,0 a $A$ & 810,0 a $A$ & 740,0 a A & 750,0 a $A$ & \\
\hline & $\mathrm{P}+\mathrm{H}$ & 1050,0 a $A$ & 1270,0 a A & 940,0 a A & 1000,0 a A & 950,0 a $A$ & \\
\hline \multirow{3}{*}{$\begin{array}{l}\text { Matéria seca } \\
\text { parte aérea }(\mathrm{mg})\end{array}$} & $\mathrm{P}+\mathrm{PC}+\mathrm{H}$ & 50,0 a $A$ & 57,0 a $A$ & 60,0 a $A$ & 70,0 a $A$ & 63,0 a $A$ & 18,65 \\
\hline & $\mathrm{P}+\mathrm{PC}$ & 48,0 a $A$ & 52,0 a $A$ & 48,0 a $A$ & 46,0 a $A$ & 40,0 a $A$ & \\
\hline & $\mathrm{P}+\mathrm{H}$ & 59,0 a $\mathrm{A}$ & 62,0 a A & 52,0 a A & 60,0 a A & 60,0 a $A$ & \\
\hline
\end{tabular}

*/ Médias de quatro repetições. Médias seguidas da mesma letra minúscula na vertical e maiúscula na horizontal, dentro de cada variável, não diferem entre si pelo teste Duncan, ao nível de $5 \%$ de probabilidade;

1/ Substratos: $\mathrm{P}=\mathrm{Plantmax}{ }^{\circledR} ; \mathrm{PC}=$ pó de coco; $\mathrm{H}=$ húmus de minhoca.

damping-off em sementeiras de diversas culturas (Melo, 1998).

Verificou-se que o incremento da população microbiana dos substratos não promoveu o crescimento das plântulas de tomateiro (Tabela 3). A ausência de diferença significativa em todas as variáveis analisadas, entre os tratamentos com microrganismos e as testemunhas, nos diferentes substratos, indicou que esses microrganismos não estão envolvidos na promoção direta do crescimento das plântulas de tomateiro. No entanto, podem apresentar eficiência no controle de patógenos transmitidos e disseminados por sementes ou mesmo no controle de doenças da parte aérea da planta, que não ocorreram durante o período experimental.

Dentro da população microbiana detectada nos diferentes substratos, além dos microrganismos benéficos às plantas, poderiam estar presentes microrganismos fitopatogênicos. Porém, nos bioensaios em casa de vegetação não foi detectada a presença de patógenos causadores de damping-off em tomateiro, sendo esta uma das características imprescindíveis a um substrato, que é a isenção de pragas e patógenos.

Os resultados obtidos são importantes para a produção comercial de mudas do tomateiro, pois demonstraram que o pó de coco se constitui em material apropriado para ser utilizado principalmente em mistura com o substrato comercial Plantmax ${ }^{\circledR}$, por ser um subproduto abundante da agroindústria do coco, de ampla disponibilidade no Nordeste do Brasil e de baixo valor no mercado, barateando o custo de produção. Esse resíduo é produzido em grandes quantidades e, até hoje, não se encontrou uso econômico para o mesmo em grande escala. Na Europa e nos Estados Unidos, esse resíduo, que tem o nome de "Coir", tem sido importado, principalmente do Sri Lanka, em grande quantidade para a horticultura intensiva, para substituir a turfa (Vavrina et al., 1996).

Do ponto de vista de viabilidade econômica, o custo para produção de mudas de tomateiro na Zona da Mata de Pernambuco em 66 bandejas com 128 células utilizando 6 sacos do substrato Plantmax ${ }^{\circledR}$ (valor unitário R $\$ 13,00$ ) é de $R \$ 78,00$. No entanto, a mesma quan- tidade de mudas pode ser obtida utilizando-se a mistura Plantmax ${ }^{\circledR}+$ pó de coco na mesma proporção (v/v) (3 sacos de Plantmax ${ }^{\circledR}=\mathrm{R} \$ 39,00+1$ saco de pó de coco $=R \$ 2,00)$ por apenas $R \$$ 41,00 , o que corresponde a uma redução do custo de produção de $47,44 \%$. $O$ custo de produção das misturas com húmus de minhoca não foram economicamente viáveis.

\section{AGRADECIMENTOS}

Os autores agradecem à CAPES e ao CNPq pela concessão de bolsas de pesquisa.

\section{LITERATURA CITADA}

BRANDÃO, E.M. Os componentes da comunidade microbiana do solo. In: CARDOSO, E.J.B.N.; TSAI, S.M.; NEVES, M.C.P. eds. Microbiologia do solo. São Paulo: SBCS, 1992. p. 1-15.

CARMELLO, Q.A.C. Nutrição e adubação de mudas hortícolas. In: MINAMI, K. Produção de mudas de alta qualidade em horticultura. São Paulo: T.A. Queiroz, 1995. p. 33-37.

CARNEIRO, J.G.A. Produção e controle de qualidade de mudas vegetais. Curitiba: UFPR/FUPEF, 1995. $451 \mathrm{p}$. 
FRAVEL, D. Commercial biocontrol products for use against soilborne crop diseases. Disponível: site USDA. URL: http://www.bar.usda.gov/psi/ bpdl/bioprod.html_Consultado em 21/11/2000.

KING, E.O.; WARD, M.K.; BANEY, D.E. Two simple media for the demonstration of pyocyanin and fluorescin. Journal Labority of Clinic Medical, v. 44, p. 301-307, 1954.

LAMAIRE, F. Physical, chemical and biological properties of growing medium. Acta Horticulturae, v. 396, p. 273-284, 1995.

LUZ, J.M.Q.; PAULA, E.C.; GUIMARÃES, T.G. Produção de mudas de alface, tomateiro e couveflor em diferentes substratos comerciais. Horticultura Brasileira, v. 18, suplemento, p. 579581, 2000.

MARIANO, R.L.R.; ASSIS, S.M.P. Quantificação de inóculo de bactérias fitopatogênicas. In: MARIANO, R.L.R. cord. Manual de práticas em fitobacteriologia. Recife: Imprensa Universitária, 2000. p. 49-52.
MEEROW, A.W. Growth of two subtropical ornamentals using coir dust (coconut mesocarp pith) as a peat substitute. Hort Science, v. 29, p. 1484-1486, 1994.

MELO, I.S. Agentes microbianos de controle de fungos fitopatogênicos. In: MELO, I.S.; AZEVEDO, J.L. eds. Controle Biológico. São Paulo: EMBRAPA, 1998. p. 17-67.

MINAMI, K. Fisiologia da produção de mudas. São Paulo: T.A. Queiroz, 1995. 129 p.

PRAGANA, R. B. Potencial do resíduo da extração da fibra de coco como substrato na produção agrícola. Recife: UFRPE, 1998. 84 p. (Tese mestrado)

PUSEY, P.L.; WILSON, C.L. Postharvest biological control of stone fruit brown rot by Bacillus subtilis. Plant Disease, v. 68, n. 9, p. 753756, 1984.
SIQUEIRA, J.O.; FRANCO, A.A. Processos microbiológicos e bioquímicos no solo. In: SIQUEIRA, J.O.; FRANCO, A.A. eds. Biotecnologia do solo: fundamentos e perspectivas. Brasília: MEC/ESAL/FAEP/ABEAS, 1988. p. 23-46.

SNEATH, P.H. Endospore-forming gram-positive cods and cocci. In: SNEATH, P.H.; MAIR, N.S.; SHARPE, M.E.; HOLT, J.G. eds. Bergey's manual of systematic bacteriology. Baltimore: Williams \& Wilckins, v. 2, 1986. p. 1104-1207.

SOAREZ, V.C.D.M. Fertilizante natural para plantas. Disponível: site Netmogi. URL: http:// www.mogi.com.br/vidaverde/humus.html_Consultado em 15/11/2000.

TUITE, J. Plant pathological methods: fungi and bacteria. Minneapolis: Burgess, 1969. 239 p.

VAVRINA, C.S.; ARMBRESTER, K.; ARENAS, M.; PENA, M. Coconut coir as an alternative to peat media for vegetable transplant production. SSWFREC Station Rpt.-VEG. 1996. 